\title{
XIV.
}

Ans der Poliklinik des Prof. Dr. Trautmann in Berlin.

\section{Ein zweiter Fall von Verletzung des Bulbus der Vena jugularis interna bei Paracentese des Trommelfells.}

\author{
Mitgetheilt von \\ Dr. Hildebrandt, \\ Assistent.
}

(Von der Redaction übernommen am 20, April 1890.)

Im Anschluss an den von Dr. Ludewig aus der Klinik von Schwartze beschriebenen Fall (Bd. XXIX. S. 234) ${ }^{1}$ ) theile ich der Seltenheit wegen ein gleiches Vorkommniss mit.

Marie L., 4 Jahre alt, aus Berlin, kam am 30. Januar 1890 in Behandlung. Vor 3 Jahren hatte sie die Masern, 6 Monate darauf heftige Ohrenschmerzen beiderseits, die bei eintretender Eiterung, welche 3 Monate anbielt, schwanden. Vor einem Jahre traten links Schmerzen auf, die nach 8 Tagen cessirten. Seit 14 Tagen soll rechts Eiterung bestehen.

Die Untersuchung ergab eine geringfügige Schwellung der Tonsilla pharyngea, ziemlich starke Schwellung der unteren Nasenmuschel, besonders rechts; Einziehung des Trommelfells beiderseits, rechts mit Adhärenz des Hammers. Exsudat war nicht vorhanden. Vor dem linken Tragus befand sich ein kleiner Auricularanhang.

Am 26. Februar klagte Patientin nach einer vorhergegangenen unruhigen Nacht plötzlich über Schmerzen im rechten Ohre. Das Trommelfell war hier glanzlos, geröthet und im hinteren unteren Quadranten vorgewölbt. Unmittelbar nach ausgedehnter Paracentese ergoss sich ein Strom dunkeln Blutes aus der Schnittwunde und floss in der Dicke eines kleinen Fingers aus dem Gehörgang bervor. Da sofort die Tamponade vorgenommen wurde, war der Blutverlust kein grosser, sondern beschränkte sich auf etwa $100 \mathrm{Ccm}$. Nach der

1) Vgl. über denselben Fall die Inaug.-Dissertation von A $\mathrm{M}$ ülle r (12. März 1890. Halle a. S.), in welcher über die Häufigkeit des Vorkommens und Aetiologie der Knochenlücken am Boden der Paukenhöhle genauere Angaben gemacht sind. Schwartze. 
Tamponade stand die Blutung auf der Stelle. Ein Abfluss von Blut durch die Tuba fand nicht statt.

Die folgende Nacht war ruhig, die Schmerzen am näehsten Tage vollkommen geschwunden. Nach 2 Tagen wurde der Tampon entfernt und der nachstehende Befund anfgenommen: Die Incision ist verheilt. Starke Retraction des Hammers and Vorspringen der hinteren Falte. Die Farbe des Trommelfells ist im vorderen Abschnitt perlgrau, im hinteren unteren Quadranten, aber auch noch auf den vorderen unteren Quadranten uibergreifend, zeigt sich eine bläulichrothe Vorwölbung von etwa Erbsengrösse. Später wiederholte Untersuchungen ergaben, dass die Grösse dieser Vorwölbung innerhalb gewisser Grenzen schwankte. Die Kuppe derselben zog sich nämlich bisweilen mehr nach unten zurïck, und dann nahm die davorliegende Partie des Trommelfells eine gelblichrothe Farbe an, was wohl eine Folge des Durchscheinens der Promontorialschleimhaut war, zumal dieser gelbliche Farbenton nach der Luftdouche wieder verschwand.

Dass die im unteren Abschnitt des Trommelfells sichtbare Vorwölbung wirklich als der durch eine Dehiscenz im Boden der Paukenhöhle durchgetretene Bulbus der Vena jugul. intern. anzusprechen ist, wird auch durch folgende Erscheinung, auf die Prof. Trautmann in diagnostischer Beziehung mich aufmerksam machte, bestätigt. Es zeigt sich nämlich, dass der auf dem vorderen unteren Quadranten befindliche Lichtreflex seine Gestalt ändert, wenn man am Halse einen ziemlich starken Druck auf die Vena jugul. intern. der rechten Seite ausübt, und zu seiner früheren Form zurücklzehrt bei Nachlass des Druckes.

Ein Nachtheil von der Venenverletzung für die Patientin wurde nicht beobachtet.

Schliesslich sei noch bemerkt, dass die Venen der rechten Gesichtshälfte, besonders die Jugul. extern., Facial. ant. und post. stärker gefullt und breiter waren, als die entsprechenden Gefässe linkerseits. Patientin ist rhachitisch gewesen und trägt noch jetzt die Spuren davon an den Gelenkenden und am Schädel. 